\title{
A Negociação da Participação nos Lucros e Resultados: Estudo em Quatro Setores Dinâmicos da Economia Brasileira
}

\author{
Antonio Carvalho Neto
}

\section{ResUMO}

A negociação da participação nos lucros e resultados, ao vincular remuneração variável a metas de lucratividade, qualidade e produtividade, passa a ser importante quando as inovações organizacionais exigem cada vez mais participação na gestão e comprometimento dos trabalhadores com os objetivos empresariais. Esse artigo é fruto da tese de doutorado do autor, resultado de vasta pesquisa realizada em São Paulo e Minas Gerais, de 1995 a 1999, onde foram tabuladas e analisadas 1.583 cláusulas de 75 acordos e convenções coletivas, abrangendo quatro dinâmicos setores econômicos brasileiros: automotor, químico, bancário e de telecomunicações. Os resultados encontrados apontam a necessidade de que a participação nos lucros e resultados seja efetivamente negociada com sindicatos que realmente tenham poder de barganha, para que se transforme no formidável instrumento de gestão que pode vir a ser, com forte probabilidade de obter maior comprometimento organizacional por parte do trabalhador. Nosso estudo mostra que isto ocorreu no setor metalúrgico, em especial no $\mathrm{ABC}$ e, em segundo plano, no setor químico pesquisado. Por outro lado, nos setores de serviços pesquisados, a negociação não ocorreu, e os programas de participação nos lucros e resultados não se efetivaram na prática.

Palavras-chaves: participação nos lucros e resultados; negociação coletiva; indústria e serviços; Brasil.

\begin{abstract}
Collective bargaining about profit sharing, productivity and performance incentives (PSPPI), when linking a variable wage percentage to profitability, quality and productivity, has become even more important in a context where organizational innovations demand larger workers' participation in management and more workers' commitment with the enterprise goals. This article is on part of the author's Ph.D. thesis and analyses a wide research accomplished in São Paulo and Minas Gerais, Brazil, from 1995 to 1999 . The author organized and analyzed 1.583 clauses of 75 collective bargaining agreements (at both the enterprise and economic sector levels), encompassing four dynamic Brazilian economic sectors: automotive, chemical, bank and telecommunication. The research showed PSPPI programs need to be negotiated with trade unions which have real bargain power in order to become the formidable managerial tool it can be. If so, there is strong probability of obtaining more organizational commitment from workers. Our research showed this happened in the automotive sector, especially in the ABC region (São Paulo) and in second plan in the chemical sector. On the other hand, in the services sectors the bargaining didn't happen and PSPPI programs haven't launched.
\end{abstract}

Key words: profit sharing, productivity and performance incentives; collective bargaining; industry and services; Brazil. 


\section{INTRODUÇÃO}

O conceito de globalização é algo vago, cuja fabricação ainda não terminou, e tampouco é algo novo na história econômica; mas, como salienta Fiori (1995), já não restam muitas dúvidas de que a atual formatação capitalista envolve dimensões tecnológicas, organizacionais, comerciais, financeiras e políticas, que se relacionam de maneira dinâmica, reconfigurando as atividades econômicas, concentrando as decisões na tríade Estados Unidos, Alemanha/União Européia e Japão.

O aumento na competição trazido pelas disputas intra e entre os novos blocos econômicos faz aumentar a pressão pela maior abertura comercial das economias nacionais, implicando políticas de privatização de empresas estatais e desregulação de mercados, aumentando ainda mais o desemprego. Como salienta a OIT (1997), muitos países em desenvolvimento na América Latina, como o Brasil, abriram as suas economias, quando elas ainda não eram minimamente competitivas internacionalmente, o que produziu muitas falências de empresas, enormes perdas de postos de trabalho e agravamento na distribuição de renda.

Esse quadro de acirramento da competição econômica levou os Estados concorrenciais europeus continentais, e ainda mais o Reino Unido e os Estados Unidos, a incentivarem a desregulamentação de direitos trabalhistas e a flexibilização do contrato de trabalho, no intuito de rebaixar os custos do trabalho. Se os efeitos desta lógica foram menos traumáticos em países como os escandinavos, foram devastadores na América Latina e no antigo bloco socialista (Teixeira, 1994; Siqueira Neto, 1996).

O impacto da nova desordem econômica no trabalho é ainda mais disruptivo em relação ao tecido social em países como o Brasil, onde o perfil do mercado de trabalho já é de acentuada heterogeneidade. O setor mais estruturado da economia, que de certa forma alimenta e se alimenta do enorme setor informal, foi o mais atingido, com desdobramentos profundos para o restante da economia, tornando ainda mais precário o emprego.

O efeito desse quadro no Brasil faz-se sentir de forma dramática. Todas as categorias estudadas na pesquisa que originou este artigo (metalúrgicos, bancários, químicos e telecomunicações), situadas em setores de ponta da economia, perderam de $30 \%$ a $40 \%$ dos postos de trabalho desde os anos 80 até 1998. E não só nossas ilhas de fordismo periférico (e aquelas próximas a elas) foram profundamente atingidas, mas também setores tradicionais, grandes empregado- 
res de mão-de-obra, que foram desestruturados com a atabalhoada abertura da economia, como o coureiro e o têxtil, além dos muitos setores privatizados (Melo, Barbosa e Carvalho Neto, 1996).

Dentro da lógica de flexibilização do contrato de trabalho, mais especificamente da flexibilização da remuneração, situam-se os programas de participação nos lucros e resultados (PLR), que vinculam parte dos vencimentos dos empregados às metas das empresas.

As inovações organizacionais presentes na atual fase da economia internacional, como parte da reestruturação produtiva, exigem maior participação na gestão e comprometimento dos trabalhadores com os objetivos empresariais. Assim, a negociação da PLR passa a ser importante nesse contexto, uma vez que vincula a remuneração variável a metas de lucratividade, qualidade e produtividade.

A remuneração variável é tendência geral, embora com ênfase diversa, dependendo do país. O que denominamos no Brasil de participação nos lucros e resultados, e que começou a ser praticado desde 1995, já vigora como prática disseminada desde os anos 70 na Suécia e, desde os anos 80, na Itália. Nos anos 90, como atesta ampla pesquisa realizada em onze países entre os mais desenvolvidos (Locke, Kochan e Piore, 1995), os programas de PLR aumentaram consideravelmente.

Sempre foi difícil negociar PLR no Brasil, tanto para trabalhadores quanto para empresários. Para o sindicalismo brasileiro mais combativo e representativo, a dificuldade foi sobretudo de natureza ideológica, já que participar dos lucros seria aceitar os valores capitalistas. Da sua parte, as empresas temiam estar criando possibilidades de os trabalhadores conhecerem o desempenho empresarial, econômico e financeiro, dando-lhes oportunidade e poder de questionar a gestão e dela participar.

Em dezembro de 1994, o governo Itamar Franco editou Medida Provisória (MP), criando a obrigatoriedade de as empresas negociarem PLR com trabalhadores, prevendo comissões de representantes por empresa. A MP não garante a participação dos sindicatos na negociação, mas uma sentença do Superior Tribunal Federal, interpretando a Constituição, a pedido dos sindicatos, obriga as empresas a aceitar a sua participação no processo. A MP prevê também critérios e condições para o pagamento da PLR, como metas pactuadas relativas a índices de produtividade, qualidade e lucratividade.

A despeito dos obstáculos, as negociações em torno da PLR parecem estar tomando impulso no Brasil. A PLR passa a ser importante para as empresas, pois favorece a busca do aumento de produtividade, da participação e do comprometimento dos trabalhadores. Para os trabalhadores também, já que oferece 
oportunidade de obter ganhos na renda, numa época difícil de se discutirem reajustes salariais, além de perspectivas de se ponderar qualificação, processo de trabalho, inovações tecnológicas e comissões de empresa, questões diretamente vinculadas a metas de produtividade, lucratividade, produção e qualidade.

Nestes processos de lançamento de programas de PLR, como acontece na implantação de tecnologias organizacionais, como apontam Stolovich e Lescano (1996), os sindicatos são forçados a lidar com ameaças, como a da quebra da solidariedade advinda da competição entre os trabalhadores, mas também podem valer-se de oportunidades, como maior autonomia e processo de trabalho menos fragmentado; resta, portanto, transformar desafios em oportunidades, ainda que o quadro seja extremamente desfavorável aos trabalhadores.

Um tema muito relevante para o chamado novo sindicalismo brasileiro, desde os seus primórdios nos anos 70, é a organização dos trabalhadores por local de trabalho (OLT), representação autônoma dos trabalhadores dentro das empresas, de fundamental importância para garantir uma negociação real e o efetivo acompanhamento dos programas de PLR em cada empresa. A discussão em torno da PLR cria oportunidades para os sindicatos se organizarem dentro das empresas, estabelecendo ligação concreta, formal ou informal, com as comissões previstas pela legislação para discutir o assunto.

De 1981 a 1996, o Sindicato dos Metalúrgicos do ABC conseguiu implantar formalmente comissões de fábrica ou delegados sindicais, com garantias de emprego, em 44 empresas do pólo automobilístico, abrangendo metade da sua base de ação (Bresciani, 1997a). As comissões de fábrica só foram consolidadas depois de muita mobilização sindical, como a greve que resultou na criação da Comissão da Ford/Taboão (SP), em 1981, além de sofrerem retaliações por parte das empresas sobre os seus membros. Tendo vencido o desafio inicial de se afirmarem, durante os anos 80, estabelecendo a representação sindical dentro das empresas, entre as comissões de fábrica mais atuantes na base metalúrgica do ABC paulista destacam-se as da Volkswagen (VW), Ford, Mercedes-Benz (MBB) e Scania, cujo desafio prioritário nos anos 90 passa a ser a reestruturação industrial (Bresciani, 1997b).

A conquista da organização sindical nos locais de trabalho, no ABC paulista, que transpôs a barreira da porta das empresas, constitui raro feito na história do sindicalismo brasileiro (Krein, 1997).

A organização dos trabalhadores por local de trabalho é um dos pontos chaves da organização sindical. A garantia de emprego para os trabalhadores exercerem funções de representação é fundamental para o sucesso dos programas de PLR, mesmo do ponto de vista das empresas, como veremos no decorrer deste artigo. 
Mathieu e Wachendorfer (1993) salientam a postura empresarial e do governo na Alemanha na valorização das OLTs como fatores para atingir os novos padrões exigidos pela competição econômica internacional. Ao contrário do que se passa no Brasil, para os autores a questão importante para os empresários deveria ser como organizar as OLTs de forma funcional para esses novos padrões de competitividade, e não recusá-las.

Em termos gerais, afora o $\mathrm{ABC}$ paulista, como a nossa pesquisa mostrou, e veremos a seguir, os empresários brasileiros estão perdendo preciosa oportunidade de utilizarem um instrumento gerencial que abriria grandes possibilidades para negociar maior comprometimento dos trabalhadores com os objetivos das empresas.

\section{Consideraçóes Metodológicas}

Partindo-se do princípio de que a PLR, para vir a ser um formidável instrumento de gestão, uma probabilidade de obter-se mais comprometimento organizacional por parte do trabalhador, cumpre que seja efetivamente negociada, a intenção desta pesquisa foi verificar qual o alcance das negociações em torno da PLR, em quatro dos setores mais dinâmicos da economia, onde os sindicatos realmente têm poder de barganha.

As empresas e os seus sindicatos foram escolhidos para esta pesquisa por dois motivos básicos: o primeiro, por estarem em setores de ponta da economia brasileira, na indústria e nos serviços, em torno dos quais se tem dado a dinâmica econômica dos anos 90; o segundo, por estarem situadas nos setores mais atuantes e representativos do sindicalismo brasileiro.

As empresas e as categorias pesquisadas estão situadas em São Paulo e Minas Gerais:

- a indústria automotriz e de autopeças paulista;

- as 3 montadoras de automóveis do ABC paulista, a Scania, a Mercedes-Benz e a Volkswagen;

. o sindicato dos metalúrgicos do $\mathrm{ABC}(\mathrm{SP})$;

- o sindicato dos metalúrgicos da região metropolitana de São Paulo;

- a indústria automotriz e de autopeças mineira; 
. a Fiat Automóveis;

. o sindicato dos metalúrgicos de Betim (MG);

. a indústria química do Estado de São Paulo;

- os sindicatos dos químicos do $\mathrm{ABC}$ e dos químicos da região metropolitana de São Paulo;

. os bancos privados, o Banco do Brasil e a Caixa Econômica Federal;

. os sindicatos dos bancários de todo o país;

. as empresas então denominadas TELEBRÁS, TELERJ, TELEMIG e CRT, antes da privatização do setor;

. os sindicatos dos trabalhadores em telecomunicações dos Estados de Minas Gerais, Rio de Janeiro e Rio Grande do Sul.

As técnicas de coleta de informações foram a da análise documental e entrevistas semi-estruturadas. Foram tabuladas e analisadas 1.583 cláusulas de 66 acordos coletivos, com negociação entre uma empresa e um sindicato de trabalhadores, e 9 convenções coletivas, com negociação setorial/regional ou nacional centralizada entre sindicatos patronais; dependendo do caso, representam milhares de empresas e sindicatos de trabalhadores, nos setores escolhidos.

O período pesquisado vai de 1995 a 1998. Para os metalúrgicos de São Paulo e do ABC, o período pesquisado foi mais abrangente, de 1995 a 1999. Foram realizadas 39 entrevistas semi-estruturadas com dirigentes sindicais e representantes empresariais dos setores pesquisados.

\section{AnÁlise dos Resultados}

\section{A Negociação da PLR no Setor de Telecomunicações Brasileiro}

A partir de 1996, os sindicatos de todo o país negociaram com as empresas de telecomunicações (TELEs) o valor pago a título de PLR, equivalente a uma parcela fixa em dinheiro, igual para todos os trabalhadores, acrescida de percentual proporcional à remuneração de cada um.

De 1996 a 1998, a posição inicial das TELEs era distribuir a PLR segundo o critério de proporcionalidade com o salário nominal de cada empregado, sem a 
parcela fixa. A proposta dos sindicatos dos trabalhadores em telecomunicações (SINTTELs) foi de uma distribuição de valor igual para todos os empregados, porquanto uma distribuição segundo o critério proposto pelas TELEs implicaria aumento do leque salarial e da concentração salarial: quem ganhasse mais receberia mais.

Prevaleceu a lógica negocial, tendo sido encontrado um meio termo, com valor misto, dividindo a PLR em duas parcelas, uma proporcional ao salário e outra fixa para todos os empregados. O piso de $\mathrm{R} \$ 1.200,00$ implicou ganho adicional para os trabalhadores de rendimentos mais baixos que este valor.

No entanto as TELEs perderam a oportunidade de dispor de um poderoso instrumento gerencial, na medida em que, nos processos negociais, o então Sistema TELEBRÁS se recusou a vincular a PLR a metas. A PLR é negociada em acordo específico, fora da data base, acabando por constituir-se em um $13^{\circ}$ salário. $\mathrm{O}$ depoimento de um dirigente da TELEMIG é muito claro na exposição das razões das TELEs para não vincular a PLR a metas.

"No Sistema Telebrás, nós nunca tivemos uma definição de metas através das quais a gente avaliaria os resultados. Em 1996, chegamos a ensaiar uma definição de metas e indicadores, que seriam passados para todas as TELEs. Lamentavelmente, não conseguimos fechar esse trabalho e, até por força da proximidade da privatização, a TELEBRÁS optou por não se ater à questão de resultados, trabalhando somente com a distribuição do lucro financeiro de balanço" (empresário entrevistado).

Os SINTTELs tinham posicionamento contrário à PLR do ponto de vista ideológico, mas tiveram de rever a sua estratégia, como explica um dos entrevistados.

"A gente defendia que uma empresa pública não visava lucro, que deveria ser repassado à população em novos serviços, melhoria da qualidade dos serviços prestados e investimentos, além de remuneração e condições de trabalho dos empregados. Eu já fui em assembléia com o pessoal mobilizado para reivindicar PLR e defendi contra; mas este processo começou a se impor de tal forma, que fomos obrigados a negociar PLR, quando o governo disse que não ia mais negociar produtividade" (sindicalista entrevistado).

A PLR se impôs, como vimos, e foi apontada tanto pelos dirigentes das TELEs quanto pelos sindicalistas entrevistados como janela de negociação que se abre, tendo os últimos destacado as oportunidades positivas que a negociação do tema propicia, no sentido de os sindicatos conhecerem mais as empresas e o processo de trabalho, além da possibilidade de criação de organizações dos empregados 
nos locais de trabalho, por meio das comissões de negociação previstas na legislação sobre a PLR.

\section{A Negociaçăo da PLR no Setor Bancário Privado e Estatal Federal Brasileiro}

Como em outras categorias pesquisadas, a discussão da produtividade desaparece após o Plano Real. Na visão empresarial, a PLR passa a substituir esta discussão. Todos os sindicalistas entrevistados afirmaram que foi a Federação Nacional dos Bancos privados, a FENABAN, que introduziu a discussão da PLR, em torno da qual foi assinado acordo coletivo nacional.

No entanto, por não estar vinculada a metas, a PLR acabou por constituir-se em abono nestas convenções centralizadas, cujo valor negociado pode ser compensado pelos pagamentos realizados nos programas de PLR de cada banco, os quais não são discutidos com os sindicatos. Para todos os sindicalistas bancários entrevistados, o acordo de PLR não possui características claras de negociação.

Os sindicalistas bancários e trabalhadores em telecomunicações foram os únicos, entre todos os setores pesquisados, que colocaram resistências à PLR do ponto de vista ideológico. A posição dos sindicalistas bancários é colocada de forma clara, como revela um entrevistado.

"O problema é a questão ideológica. Tem dirigente sindical que acha o máximo a PLR. Eu acho um absurdo. É uma forma de retirar a solidariedade entre os bancários, de o banco relacionar-se diretamente com seus funcionários, sem o sindicato [...] é uma forma de rebaixar o salário real, de haver uma competitividade imensa entre os funcionários, de acirrar o espírito individualista" (sindicalista entrevistado).

Ainda assim, reconhecia-se que a PLR poderia ser uma oportunidade positiva.

"Toda introdução de formas de remuneração apoiadas em indicadores de desempenho da empresa cria a oportunidade da presença do sindicato mais próximo do local do trabalho, no sentido de conhecer mais a empresa, de estar mais qualificado para discutir com ela. Agora, se o banco não discute indicadores, então fica também uma coisa meio esquisita [...] Eu acho que a PLR seria a principal brecha pela qual tem que entrar o movimento sindical”.

Acerca da PLR estar desvinculada de metas, os empresários se explicam. 
"A idéia é não cercear, que cada banco tenha o seu programa. Nós escolhemos o lucro, porque é um dos itens mais importantes na avaliação da instituição bancária" (empresário entrevistado).

De fato, os empresários do setor bancário estão perdendo ótima oportunidade para conseguir a adesão do trabalhador aos seus objetivos, quando se negam a negociar a PLR vinculada a metas com os sindicatos. Impor programas de forma unilateral a comissões que não têm estabilidade, como se vem fazendo, não caminha no sentido de um envolvimento de fato do trabalhador, já que comprometimento pressupõe capacidade de criticar e influir de forma propositiva e independente.

A negociação coletiva centralizada da PLR, em nível nacional, foi mantida até o fim do período pesquisado. Do ponto de vista sindical, a descentralização das negociações sobre PLR é inevitável, dada a sua natureza localizada. Para os sindicalistas bancários entrevistados, não haveria problemas em descentralizar, desde que princípios gerais fossem estabelecidos em nível nacional, como a garantia de estabilidade para a comissão de trabalhadores em cada banco, acompanhamento por parte dos sindicatos das eleições dos membros destas comissões e o fornecimento de todos os dados sobre a situação da empresa.

\section{A Negociação da PLR no Setor Químico das Regióes Metropolitanas de São Paulo e do ABC}

Nos dois primeiros anos após o Plano Real o aumento real não se deu mais a título de produtividade, confirmando a tendência empresarial de não mais discutir essa questão a partir da desindexação da economia, vinculando essa discussão à concessão da PLR.

Se bem que apresente possibilidades reais para abarcar a negociação sobre produtividade, a PLR não se incorpora aos salários, razão pela qual reivindicações sobre produtividade continuam nas pautas dos sindicatos dos trabalhadores.

Nos dois primeiros anos depois do Plano Real os químicos continuaram conquistando aumentos reais, ainda que residuais. Já nos processos negociais subseqüentes (1996/1998), os químicos passaram a sofrer perdas sobre o Índice Nacional de Preços ao Consumidor (INPC) acumulado. Esse movimento de perdas inicia-se após o primeiro ano de introdução da PLR. Os empresários entrevistados disseram claramente que "numa condição como essa era impossível dar aumento real; então a partir de 1995 nós concedemos um abono referente à PLR". Fica claro o caráter de substituição dos aumentos reais pela PLR que, nas convenções centralizadas, não teve nenhuma vinculação com metas, o que seria desejável, tanto do ponto de vista gerencial, quanto do ponto de vista dos trabalhadores, que têm 
mais possibilidades de discutir questões como a qualificação e o processo de trabalho, vinculadas à exigência de maior produtividade e qualidade dos produtos.

Em relação à PLR, os sindicatos dos químicos negociaram, a partir de 1995/ 1996, uma cláusula, nas suas convenções coletivas centralizadas, que assegura aos empregados das empresas que não tenham programa próprio um valor fixo de $\mathrm{R} \$ 300,00$, correspondente a cerca de $50 \%$ no ABC, ou $66 \%$ em São Paulo, do salário médio da categoria, independentemente de metas. A falta de vinculação a metas indica a concessão da PLR como mero abono. O trecho da entrevista concedida por um empresário deixa isso claro.

"Na verdade, nós negociamos um abono referente à PLR, compensatório da não existência de aumento real. Em 96, fizemos o mesmo. Não fizemos com metas, porque num universo tão diferenciado como o nosso não dá. Só o setor plástico do Estado de São Paulo tem 4.000 empresas! A PLR tem outra vantagem, principalmente hoje, em que, infelizmente, os ônus sociais sobre os salários são bastante expressivos" (empresário entrevistado).

Essa cláusula, que assegura a PLR para os trabalhadores de todas as empresas do setor químico, foi saudada por todos os empresários e trabalhadores entrevistados como avanço. Os sindicatos dos químicos não aceitaram colocar ressalvas na convenção que desobrigassem as micros e pequenas empresas do seu cumprimento, já que este amplo universo de trabalhadores é que foi mais beneficiado com a negociação centralizada, como fica claro no depoimento de um dirigente sindical.

"Foi uma necessidade de ambas as partes. $\mathrm{O}$ sindicato não tem pernas para negociar a PLR com as 600 empresas da base. Se tivéssemos representante sindical por empresa, teríamos condições, mas não temos! O sindicato patronal foi até pressionado pelas empresas menores para não colocar isso na convenção" (sindicalista entrevistado).

A negociação coletiva centralizada, portanto, tem um papel regulador, ao estabelecer as mesmas normas de remuneração para ampla gama de micros e pequenas empresas.

$\mathrm{Na}$ amostra analisada de acordos coletivos por empresa, observamos que as negociações descentralizadas referentes à PLR em sua maioria a vincularam a metas, abrindo possibilidades para ganhos superiores ao valor fixo negociado na convenção centralizada.

Se a negociação centralizada possibilitou ganho aos trabalhadores de micros e pequenas empresas, as negociações descentralizadas possibilitaram ganhos muito mais expressivos aos trabalhadores das empresas maiores, onde os sindicatos 
dos químicos têm maior poder de intervenção. No segmento petroquímico do $\mathrm{ABC}$, por exemplo, em duas empresas o sindicato chegou a conquistar de 4 a 6 salários extras a título de PLR em um só ano.

Nos acordos coletivos de PLR, negociados entre o Sindicato dos Químicos do $\mathrm{ABC}$ e empresas maiores, tais como a Perstorp do Brasil, Polibrasil Polímeros Compostos, Kopoll Filmes, COFADE - Sociedade Fabricadora de Elastômeros, Cabot e Tintas Coral (1996/1997 e 1997/1998), de maneira geral enfatiza-se produtividade, qualidade e segurança; os valores a serem distribuídos se encontram condicionados ao alcance de metas. Uma faixa de cerca de $80 \%$ a $90 \%$ do valor a ser pago a título de PLR, nesses acordos, está vinculada a metas que dizem respeito à produtividade e à qualidade. Uma faixa de cerca de $10 \mathrm{a} 20 \%$ do valor da PLR é distribuída entre metas relativas a absenteísmo e prevenção de acidentes.

Os acordos de 1996/1997 e 1997/1998 da Perstorp são um elucidativo e comum exemplo de PLR condicionada a metas e seus respectivos pesos no setor químico: produtividade $(45 \%)$, redução de resíduos (10\%), contas a receber $(15 \%)$, entrega de produto (24\%), absenteísmo (3\%) e acidentes de trabalho (3\%). Para $100 \%$ das metas atingidas, o valor a ser distribuído é da ordem de $\mathrm{R} \$ 600,00^{(1)}$. Se forem atingidas mais de $100 \%$, o valor passa a $120 \%$.

A PLR abre muitas possibilidades de negociação, como na empresa Cabot (1997/1998), onde as metas individuais correspondem a 30 pontos, vinculadas à avaliação de desempenho. As metas coletivas vinculam-se à qualidade: certificação pela ISO9000; limpeza e organização de áreas comuns; média de reclamações de clientes; redução de custos; metas por departamento; zero acidentes com afastamentos. Se $90 \%$ das metas forem atingidas, a PLR corresponde a um salário; para 100\%, 1,5 salário; para 110\%, 2 salários.

Constatamos que alguns dos acordos de PLR caracterizam-se por iniciativas das empresas, sem a participação do sindicato. Esses acordos coletivos foram assinados entre a Solvay, a Chevron, a Kolynos e as suas respectivas comissões de representação de trabalhadores, constituídas para tal fim (os membros dessas comissões não têm estabilidade no emprego).

Os acordos de PLR dessas empresas não possuem diferenças mais significativas entre si e em relação aos acordos de PLR negociados com o sindicato, a não ser no caso da Solvay, onde o peso da meta freqüência de acidentes eleva-se de 5\% para 9\% (1997/1998). Nos três anos de acordos analisados, a ocorrência de acidente fatal reduz a zero o peso dessa meta na composição da PLR. Essa punição rigorosa, rara nos outros acordos, culpa os trabalhadores pelos acidentes fatais, como se a responsabilidade fosse exclusivamente deles. 
Cláusulas assim leoninas apontam a necessidade de garantias de emprego para as comissões de trabalhadores que, assim, teriam maiores condições de coibir esse excesso de rigor. Os sindicatos dos químicos desenvolveram uma estratégia para conseguir negociar a PLR com esse tipo de empresa: garantiram nas negociações o poder de substituir as comissões, caso uma assembléia dos trabalhadores da empresa aprove.

\section{A Negociação da PLR no Setor Metalúrgico das Regiōes Metropolitanas de São Paulo, do ABC e de Betim}

Neste tópico, serão analisadas: as negociações coletivas centralizadas nas convenções do setor metalúrgico das regiões do $\mathrm{ABC}$, metropolitana de São Paulo e de Betim (MG); as negociações coletivas descentralizadas por empresa, em quatro grandes montadoras de automóveis: a Volkswagen, a Mercedes-Benz e a Scania, no ABC; a Fiat, em Betim.

As empresas do complexo automotor estão organizadas em sindicatos patronais, como o das grandes montadoras de automóveis, o Sindicato dos Fabricantes de Veículos Automotores (SINFAVEA). A indústria de autopeças está organizada no Sindicato Patronal da Indústria de Autopeças (SINDIPEÇAS), e a indústria de máquinas, no SINDIMAQ.

Esses três sindicatos patronais são filiados à Federação das Indústrias do Estado de São Paulo (FIESP), e realizam negociações coletivas centralizadas com os Sindicatos dos Metalúrgicos de São Paulo e do $\mathrm{ABC}$, que têm validade para todo o setor metalúrgico, abrangendo não só as regiões metropolitanas de São Paulo e do ABC, como também boa parte do Estado de São Paulo. Estas negociações centralizadas redundam em convenções coletivas.

Em Minas Gerais, a convenção coletiva dá-se entre o Sindicato dos Metalúrgicos de Betim, de um lado, e a Federação das Indústrias do Estado de Minas Gerais (FIEMG), vários sindicatos patronais filiados a esta, como o Sindicato da Indústria da Fundição e o Sindicato da Indústria Mecânica de Minas Gerais, e também sindicatos nacionais, como o SINFAVEA.

O Sindicato dos Metalúrgicos de Betim negociou a inclusão, em convenção coletiva, de cláusula referente à PLR, enquanto o sindicato do $\mathrm{ABC}$ só negociou este tema no nível das empresas, de forma descentralizada. O sindicato de São Paulo negociou a PLR inicialmente na convenção centralizada com o SINDIPEÇAS, mas depois priorizou a negociação da PLR por empresa. Durante as entrevistas, os sindicalistas de São Paulo e do ABC deixaram claro que não é vantagem para os trabalhadores incluir a PLR nas convenções, porque esta acaba 
por substituir a negociação por reajustes salariais, numa posição coincidente com os sindicalistas bancários.

Nas convenções coletivas de Betim, no início deste processo, em 1995/1996, a PLR era maior, de $50 \%$ a $70 \%$ do salário, além de valer para qualquer empresa. A partir de 1996/1997, a tônica foi diferenciar o valor a ser pago, de acordo com o número de empregados (empresas maiores pagaram mais); neste período, a PLR caiu de valor em cerca de $20 \%$ a $25 \%$ do salário, e as empresas que concedessem PLR em programas próprios foram autorizadas a descontar o valor pago por elas dos valores estabelecidos na convenção.

Para os trabalhadores das pequenas empresas, que são a grande maioria na base do sindicato de Betim, com salários em média de $\mathrm{R} \$ 300,00$, esta garantia de PLR, mesmo que vinculada a lucros e não a resultados (nas convenções centralizadas, a PLR não esteve relacionada com metas), representou uma vantagem. A inclusão da PLR na convenção garante a um grande contingente de trabalhadores um mínimo que seja de melhoria na remuneração, enquanto os sindicatos do $\mathrm{ABC}$ e de São Paulo precisam desenvolver um trabalho imenso e interminável para negociar a PLR nas pequenas empresas.

Em termos de oportunidades positivas no novo contexto negocial, a partir da segunda metade dos anos 90, a PLR é apontada por $90 \%$ dos trabalhadores entrevistados nas três regiões metalúrgicas como o tema mais importante no período pesquisado. $\mathrm{O}$ depoimento extraído da entrevista de um deles é muito claro a respeito.

"Do ponto de vista de ganhos para o trabalhador, tem-se intensificado muito a questão da PLR, que antes já era uma prática, um abono por resultado. Com a queda da inflação, ela passou a ter um peso significativo, em média de 1 a 3 salários por ano [...] os trabalhadores puderam, a partir das informações, da negociação da PLR, ter um conhecimento melhor da empresa, dos seus indicadores. $\mathrm{E}$ isso tem-se tornado, aqui no $\mathrm{ABC}$, uma prática bastante forte; está no cotidiano dos trabalhadores" (sindicalista do $\mathrm{ABC}$ entrevistado).

O total dos empresários entrevistados considerou como oportunidades positivas, no novo contexto negocial dos anos 90 , tanto a PLR quanto a flexibilização da jornada. Os empresários entrevistados $(75 \%)$ também consideraram a PLR uma inovação organizacional, devido à possibilidade de vinculá-la a metas de qualidade e produtividade, como enfatiza um empresário entrevistado.

"Antes, com a inflação, chegava a data base você não podia dar um tratamento ao salário como gostaria de dar, que seria a remuneração versus o 
produto que se faz. Eu percebo, nesses três últimos anos, que as lideranças mais conscientes da realidade, têm tido uma discussão muito séria a respeito da [...] recomposição salarial, dentro de uma visão que não é mais aquela do resíduo inflacionário colocado no salário e tudo bem, mais um aumento de [...] produtividade, e fim, está tudo resolvido. Não. Quero reconhecer isso como um ponto de convergência, porque todos nós temos que reavaliar a questão salarial, senão perdemos competitividade" (empresário entrevistado).

Todos os dirigentes e assessores entrevistados do Sindicato dos Metalúrgicos de São Paulo enfatizaram a sua autêntica cruzada em defesa da negociação da PLR em qualquer empresa, independentemente do tamanho. O extrato da entrevista de um deles atesta claramente a defesa da PLR como fonte de oportunidades para a ação sindical, e os pontos coincidentes com o discurso empresarial da competitividade.

"PLR [...] realmente, a gente entrou de cabeça. Com a inflação caindo, percebemos que iam endurecer as negociações. Hoje, muitos sindicatos não conseguem 2, 3\%. Nós vimos na PLR uma alternativa de ganhos para o trabalhador. É também a maneira da gente começar a entrar dentro da fábrica, fazer com que o trabalhador tenha participação maior no processo produtivo. Aquele delegado sindical de antigamente, que tinha que saber fazer uma greve, está numa situação diferente, tem que conhecer o processo produtivo para discutir programas de metas, qualidade do produto, para que este seja competitivo!" (sindicalista de São Paulo entrevistado).

Acordos de PLR entre empresas como a Lorenzetti, fábrica de chuveiros, e a Multibrás, eletrodomésticos, e o Sindicato dos Metalúrgicos de São Paulo são exemplos de como em São Paulo os acordos são vinculados a metas de qualidade e produtividade, além de metas de redução do absenteísmo e dos acidentes de trabalho.

No ABC, as negociações sobre a PLR deram-se de forma totalmente descentralizada, por empresa. A Fiat também negociou PLR em separado, com o sindicato de Betim. A Mercedes-Benz foi a primeira das quatro montadoras a negociar PLR, em 1993/1994, um ano antes da Medida Provisória do governo sobre a questão, revelando, mais uma vez, o pioneirismo do sindicalismo do $\mathrm{ABC}$, e o seu papel de benchmarking sindical no país. A PLR, nessa primeira versão na MBB, consistia em valor fixo, independentemente de metas. No ano seguinte, também foi a MBB a precursora, agora na vinculação da PLR a metas de qualidade, produção e redução do absenteísmo.

Como em São Paulo, o Sindicato dos Metalúrgicos do ABC defendeu a vinculação da PLR a metas desde o primeiro instante, demonstrando perceber as 
inúmeras possibilidades que o tema abre para a intervenção e organização sindicais no local de trabalho. Como dizem dois dirigentes sindicais entrevistados:

"a nossa resolução foi de fazer acordos por resultados, e não por lucro, de ter metas claramente administráveis, que cada um pudesse entender [...] é uma chance rara para os trabalhadores saberem que intenções a empresa tem consigo própria naquele ano [...] uma chance para agir dentro das empresas" (sindicalista entrevistado no $\mathrm{ABC}$ ).

"Quando você fica sabendo quais são os reais problemas da empresa, você também sabe quais são os problemas ou os avanços que o sindicato pode ter na empresa; você tem elementos para interagir e fazer uma ação sindical. O que vale a pena é estar cada vez mais dentro do local de trabalho para fazer a negociação. Nós temos mais vantagens do que desvantagens em estar no local de trabalho" (sindicalista entrevistado no ABC).

A Força Sindical é adepta entusiástica da PLR vinculada a metas; no interior da Central Única dos Trabalhadores (CUT), só há resistências minoritárias, como a dos sindicatos, em cuja direção se encontram lideranças afinadas com uma ideologia de esquerda mais ortodoxa, como a dos metalúrgicos de São José dos Campos, cuja direção é ligada ao Partido Socialista dos Trabalhadores Unificados (PSTU), que não aceita "compromissos com o capital".

Em 1995/1996, dois anos depois da MBB, a Scania e a Fiat introduziram os seus programas de PLR, negociados com os sindicatos, vinculados ao cumprimento de metas do mesmo tipo da $\mathrm{MBB}$, quais sejam: produção, qualidade e absenteísmo. Talvez devido à reestruturação da $\mathrm{MBB}$, ocorrida neste ano, e às traumáticas demissões (cerca de 1.600 trabalhadores em 1995), a empresa passou a pagar valor fixo, sem metas. Em 1996/1997, a MBB retorna à vinculação com metas; a Fiat e Scania mantêm seus programas e a Volkswagen finalmente inaugura o seu.

A Fiat é a única das quatro montadoras pesquisadas a vincular o pagamento de qualquer parcela da PLR ao cumprimento de metas, desde o início do seu programa, não antecipando uma parte que depois não poderia ser descontada, caso as metas não fossem atingidas. A General Motors procede como a Fiat. As outras três montadoras pesquisadas (VW, MBB e Scania) pagam a maior parte, adiantada (cerca de $60 \%$ do valor total), em valor fixo, independentemente de metas, a título de incentivo, numa espécie de compromisso prévio. Essa parcela fixa acaba transformando-se, na prática, mais num abono do que numa PLR. O restante (40\%) é que assume a característica de PLR de fato, na MBB, Scania e VW. 
Somente em 1997/1998, a MBB e a Scania passam a exigir um mínimo de metas cumpridas para pagar os $60 \%$ antecipados ao longo do ano, o que sugere que as outras montadoras se aproximam da postura gerencial da Fiat, neste aspecto específico. Os metalúrgicos do $\mathrm{ABC}$ chegaram a receber quase $\mathrm{R} \$ 3.000,00$ de PLR em um ano, conforme a montadora. Os valores pagos a título de PLR (1997/1998) nas quatro montadoras, em relação a um valor de referência do salário de um trabalhador horista na Fiat $(\mathrm{R} \$ 800,00)$, que denominaremos aqui em termos de comparação do salário-Fiat, oscilaram, como se explicita em seguida.

- A faixa inferior: cerca de um salário-Fiat na Fiat e cerca de 3 salários-Fiat na Scania, correspondentes a 1,7 do salário horista na Scania.

- A faixa superior: 3,5 salários-Fiat na VW, correspondentes a mais de 2 salários de um horista na VW, e 3,6 salários-Fiat na Scania.

Os valores mais baixos, nas duas faixas, foram pagos pela Fiat, o que se coaduna com a sua política de praticar salários mais baixos (a metade) que as demais montadoras no $\mathrm{ABC}$.

\section{Conclusóes}

Em todos os setores pesquisados a PLR se impôs como o principal tema, visto como uma oportunidade positiva no contexto negocial dos anos 90 por $85,71 \%$ dos empresários e $91,30 \%$ dos sindicalistas entrevistados.

As negociações em torno da PLR passaram a ser vistas como possibilidade de discutir a organização do processo de trabalho, treinamento e qualificação profissional, polivalência, gestão participativa e OLTs. Sindicalistas e empresários já perceberam essas possibilidades, como mostraram tanto a análise das convenções e acordos coletivos quanto as entrevistas realizadas (vide Tabelas 1 e 2).

Os sindicalistas bancários e de telecomunicações entrevistados foram os únicos entre todos os setores pesquisados que colocaram resistências à PLR do ponto de vista ideológico: os de telecomunicações, em razão do que entendiam por serviço público (reinvestir o lucro em melhoria dos serviços à população), e os bancários em razão da quebra de solidariedade de classe e da possibilidade de negociação fora do sindicato e individualizada. 
Tabela 1: Temas Acordados entre Sindicato e Empresas a partir de 1993, Considerados os Mais Importantes pelos Representantes dos Trabalhadores

\begin{tabular}{lc}
\hline \multicolumn{1}{c}{ ITENS } & $\%$ \\
\hline Participação nos lucros e resultados & 100,00 \\
Qualificação/formação profissional & 21,74 \\
$\begin{array}{l}\text { Participação do sindicato na introdução de inovações tecnológicas e } \\
\text { organizacionais }\end{array}$ & 17,39 \\
Redução da jornada semanal média de trabalho (sem redução de salário) & 17,39 \\
Flexibilização da jornada & 17,39 \\
Não houve ganhos advindos do processo negocial no período & 8,69 \\
Condições de trabalho & 4,35 \\
\hline
\end{tabular}

Fonte: entrevistas com 25 representantes dos trabalhadores dos 7 setores pesquisados.

Obs: A soma da freqüência relativa é superior a $100 \%$ por ter sido dada mais de uma resposta.

Tabela 2: Temas Acordados entre Sindicato e Empresas a partir de 1993, Considerados os Mais Importantes, segundo os Empresários

\begin{tabular}{lc}
\hline \multicolumn{1}{c}{ ITENS } & $\%$ \\
\hline Participação nos lucros e resultados & 100 \\
Flexibilização da jornada & 57,14 \\
\hline
\end{tabular}

Fonte: entrevistas com 14 representantes dos empresários dos 7 setores pesquisados.

Obs: A soma da freqüência relativa é superior a $100 \%$ por ter sido dada mais de uma resposta.

Essas resistências não impediram que o tema se impusesse nesses dois setores. Ao contrário dos setores metalúrgico e químico pesquisados, os empresários do setor bancário e de telecomunicações estão perdendo uma ótima oportunidade para conseguir a adesão do trabalhador aos seus objetivos, quando se negam a negociar a PLR vinculada a metas com os sindicatos. A PLR nos setores bancário e de telecomunicações teve característica de abono, sem vinculação a metas, vindo a substituir em parte os reajustes salariais.

No setor bancário privado, há programas isolados de PLR que excluem os sindicatos da negociação e acompanhamento. Nesses casos, a gerência perde ótima oportunidade de envolver os trabalhadores com os objetivos das empresas de forma mais duradoura, ao negar-lhes o direito à opinião crítica e coletiva, que se daria por meio do sindicato, como a pesquisa constatou que ocorre nos setores metalúrgico e químico do ABC e de São Paulo. 
Os sindicatos dos trabalhadores dos dois setores de serviços pesquisados, por sua vez, também perderam a oportunidade de negociar aspectos da gestão das empresas, do processo de trabalho, dos programas de qualificação e de cargos e salários que a negociação da PLR possibilita. Como ficou claro nas entrevistas dos sindicalistas, estes admitiram que têm de preparar-se mais para negociar essas novas questões.

Já nos setores químico e metalúrgico, a PLR foi negociada vinculada a metas. A avaliação dos empresários entrevistados é a de que, do ponto de vista gerencial, a negociação da PLR constituiu importante impulsionador da produtividade dos trabalhadores e do maior comprometimento deles com os objetivos das empresas.

No setor metalúrgico do ABC, a PLR foi muito mais negociada e acompanhada pelas comissões de fábrica e pelo sindicato; a avaliação da gerência das montadoras pesquisadas, quanto ao envolvimento dos trabalhadores com os programas e quanto aos seus resultados, é muito positiva.

No geral, houve mais resultados positivos em relação à remuneração nas negociações ocorridas nos setores industriais pesquisados (químico e metalúrgico) do que nos setores de serviços (bancário e telecomunicações), e, entre os setores industriais, mais no metalúrgico do $\mathrm{ABC}$ do que em São Paulo, e mais em São Paulo do que em Betim.

A pesquisa indica que os programas de PLR têm crescido e que esta tende a ser uma estratégia gerencial cada vez mais adotada no país. Como vimos, apesar das extremas dificuldades em que se encontram os sindicatos, os metalúrgicos do $\mathrm{ABC}$ em especial, e os químicos, em segundo lugar, se destacaram na negociação da PLR, obtendo vantagens para os trabalhadores.

Da parte das empresas, os resultados encontrados nos indicam que, quando realmente negociados com sindicatos de trabalhadores representativos, que têm liderança reconhecida pelos trabalhadores e, melhor ainda, quando acompanhados no nível da empresa por comissões de empregados livremente eleitas e com garantia de emprego (estabilidade temporária igual à do dirigente sindical, como no caso do $\mathrm{ABC}$ ), que podem exercer a crítica e também o apoio ao programa sem fortes retaliações, os programas de PLR aumentam o nível de comprometimento organizacional, bem como melhoram os indicadores de desenvolvimento econômico.

\section{Nota}

${ }^{1}$ Correspondente a cerca de um salário médio da categoria no ABC. 


\section{ReferênCIAS Bibliográficas}

BRESCIANI, L. P.

Os desejos e o limite: reestruturação industrial e ação sindical no complexo automotivo brasileiro. In: LEITE, M. DE P. (Org.). O trabalho em movimento : reestruturação produtiva e sindicatos no Brasil. Campinas : Papirus, 1997a.

Na zona do agrião: comissões de fábrica, trabalho e negociação coletiva na indústria automobilística brasileira. In: ARBIX, G.; ZILBOVICIUS, M. (Orgs.). De JK a FHC : a reinvenção dos carros. São Paulo : Scritta, 1997b.

FIORI, J. L.

A globalização e a 'novíssima dependência'. Série Textos para Discussão, n. 343, ago. 1995.

KREIN, J. D.

Reestruturação produtiva e sindicalismo. In: CARLEIAL, L.; VALLE, R. Reestruturação produtiva e mercado de trabalho no Brasil. São Paulo : Hucitec-ABET, 1997. p. 439-479.

LOCKE, R. M.;

KOCHAN, T. A.;

PIORE, M. J. (Eds.).

Employment relations in a changing world economy. Cambridge : MIT Press, 1995.

MATHIEU, H.;

WACHENDORFER, A.

Contrato coletivo, negociação coletiva, competitividade e crescimento: principais conceitos e quadro comparativo. Série Seminários, n. 26, out. 1993.

MELO, M. C. DE O. L.;

BARBOSA, A. C. Q.;

CARVALHO NETO, A. M. DE.

As relações de trabalho no Brasil: uma apresentação e análise. Universidade de Bremen/ Alemanha, 1996. relatório de assessoria de pesquisa.

OIT - OFICINA INTERNACIONAL DEL TRABAJO.

El trabajo en el mundo 1997-98 : relaciones laborales, democracia y cohesión social. Genebra, 1997.

SIQUEIRA NETO, J. F.

Flexibilização, desregulamentação e o direito do trabalho no Brasil. In: Crise e trabalho no Brasil, modernidade ou volta ao passado? São Paulo : Scritta, 1996. 
STOLOVICH, L.;

LESCANO, G.

El desafío sindical de la calidad total. Revista Latinoamericana de Estudios del Trabajo, año 2, n. 4, 1996.
TEIXEIRA, A.

O ajuste impossível: um estudo sobre a desestruturação da ordem econômica mundial e seu impacto sobre o Brasil. Rio de Janeiro : Editora da UFRJ, 1994. 